\title{
Technology as a Determinant of Object Shape
}

\author{
Denis A. Coelho and Filipe A. A. Corda \\ Universidade da Beira Interior \\ Portugal
}

\section{Introduction}

In a globalized world, we are confronted everywhere with the encouragement to consumption, the purchase of goods and services. This is something characteristic of the consumer society in which we live, whether it is caused by consumption needs and their satisfaction or because saturation has already set in, or it may even be caused by social statement (Baudrillard 1995).

The intention of this chapter is to focus on the study of technology as a determinant of the shape of products that incorporate technology. The acceptance of a product by consumers, and how important the shape and look of it is to the success of the product, has been previously studied (Bloch 1995). Research has also been carried out to study the determinants of the shape of products (Crilly, Moultrie \& Clarkson 2009), which shows that several aspects determine the final shape of a product. The form development process is driven by the designers' efforts to guide or constrain the way in which the product will be experienced, and the success of the final design may be determined by the degree of correspondence between designer intent and consumer response (Crilly, Moultrie \& Clarkson 2009). This chapter does not intend to focus on all determinants of product shape and does not aspire to focus on the acceptance of a product on the market or to reflect on the role of the personal taste of the industrial designer in determining the shape of the product. The aim of this chapter is to study the influence of one aspect in particular, technology as a determinant of the form of products, for products that embed technology.

The study of materials and their development also fits this line of inquiry, since there is a synergy between the development of technology and of materials. This historical relationship, while not the main focus of this work, is also of interest and merits some comments. The advent of new materials and the development and improvement of others makes it possible to improve the application of new technologies and the consequent development of new products. Man, machine, materials and production are closely linked in modern industry and this link is becoming increasingly strong. Advanced materials are critical to many new technological applications, since the latter depend strongly on the advances of the former (i.e. the high-speed train, Maglev, is based on technology already developed and tested but its large-scale implementation awaits improvements in materials technology so that cryogenic preservation can be maintained economically, so that it may be possible to create the magnetic levitation and consequent propulsion of the vehicle). 
Mastering the state of the art in materials and technological solutions offers vast opportunities, due largely to a greater understanding and greater control of their basic characteristics. As such, new materials play an important role in the development of innovative technologies. For example, without knowledge of materials such as quartz crystal or piezoelectric ceramics, the production of energy that occurs with the deformation of these materials could not be put to use. Knowledge about materials catalyzes more technological knowledge. A recently created metallic material, with platinum-based nanopores, expands and contracts under the action of an electric current thereby converting electrical energy into mechanical energy and vice versa, depending on the state of the material. In conclusion, materials in general and bio-mimetic nano-materials in particular, form together with intelligent materials and organic polymers, among other materials, a wide range of examples of materials whose importance is recognized in the field of technology and product design.

The approach that is central to this chapter is bounded by the larger process of industrial design, where it gives a contribution that may take place at the stage of concept generation as well as the stage of detailed design. The bounding process of design that is considered is in line with the report of Lewis and Bonollo (2002). These authors performed an experimental investigation to unveil the design skills most influential to professional success, in order to have design education adequately train students in those skills. In order to structure their research, these authors harnessed a five stage operational process of design, based on selected literature of their choice (Hales 1991). This process is comprised of five sub-ordinate processes (Table 1).

Product development is part of any company's industrial innovation process (Roozenburg \& Eekels 1995). Industrial innovation includes all activities preceding the launch of a new product into the marketplace, such as basic and applied research, design and development, market research, production, distribution and sales. The development of new technological possibilities has triggered the search for applications, which in many cases has led to the unveiling of new products. In such cases it is not uncommon that the design process instead of centring on the user and the potential market is driven by the search for technological applications.

In practice, technology influenced design may lead the way, in some cases, to a simplification of the design process depicted in Table 1, as little room is given to new concept generation, since the concept is determined by the application of technology to enable a particular functionality and as such, circumvents the search for new ideas, and promotes the continuation of a particular product archetype. Such archetype may well be tied to market requirements and perceived consumer acceptance, as well as to technological constraints and salient features that hamper shape alterations. What is proposed in this chapter is to study the influence of technology as a determinant of the final shape of a product that incorporates technology. This is intended to demonstrate how this is a key aspect for the possible deconstruction of product archetypes which have endured for many years. To this end, some new product concepts are presented that incorporate emerging technologies, reflecting a change of form, distinct from the existing hitherto.

This chapter seeks to demonstrate the influence of technology in the form of the product. It also seeks to unveil cases of product shape changes brought about from the influence of technology in three categories given below: 
1. Changing the form in a visible way (but not the product as an object ceases to exist);

2. Changes in the product in situations in which technology changes in not reflected in changing the form of the product much but is responsible for modification of performance (performance), keeping the existing product as an object;

3. Cessation of existence of the product as such, in situations where the change in technology leads to a deconstruction of the product as an object, leaving behind the archetypes and stereotypes in a way hitherto associated with the product.

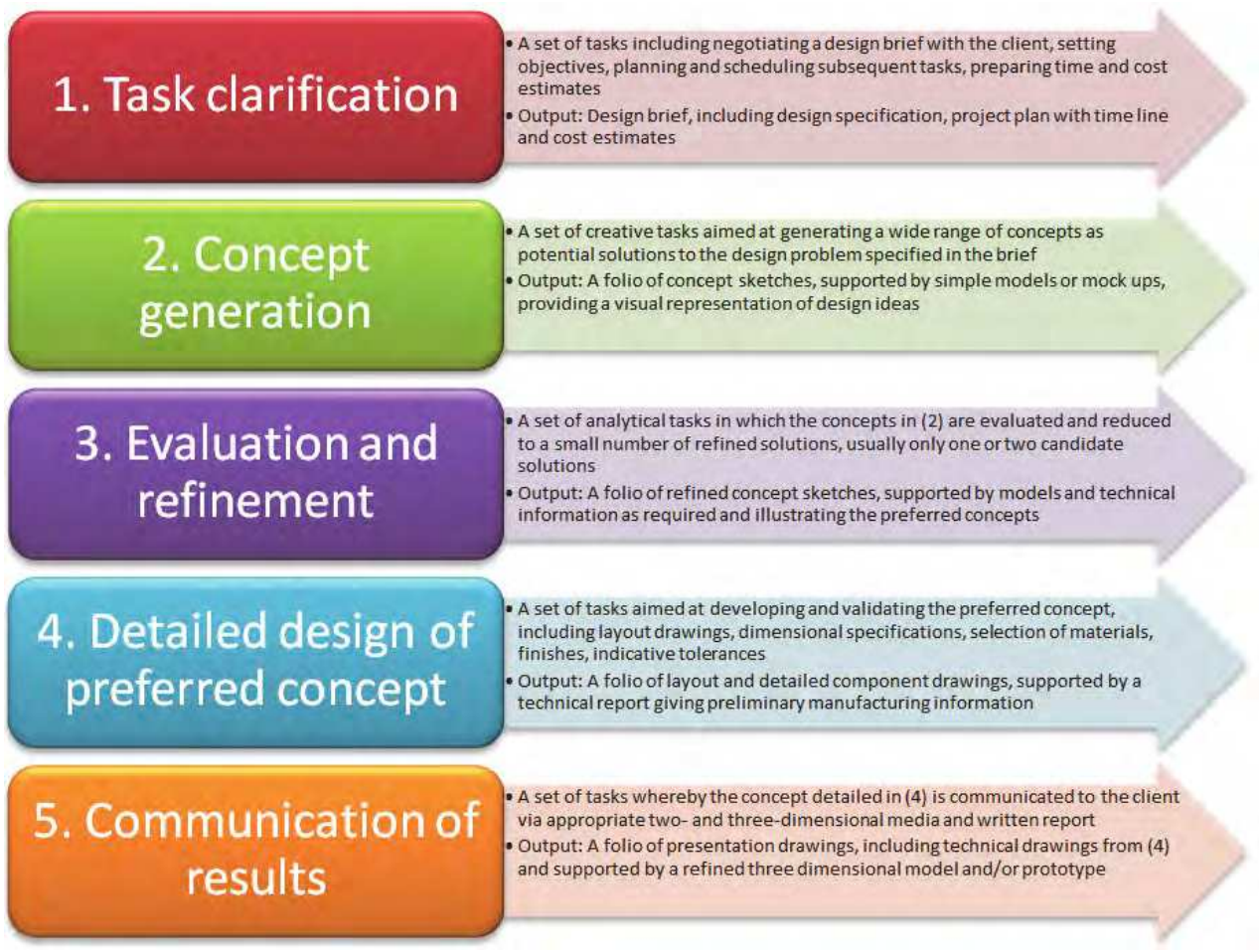

Table 1. Operational Model of the Design Process (Lewis \& Bonollo 2002, Hales 1991)

\section{Aims}

There is an important question that impinges on the future of the practice of industrial design - will there be objects that are at risk of deconstruction, to merge with the environment, in view of the technologies that are developed for the near future and that will replace the existing ones? The overall objective of the work (Corda 2010) reported in this chapter was to carry out a survey of the evolution of form, taking into account the technology of a selected range of consumer technology products in order to deconstruct archetypes that are fixed and propose new concepts, with particular regard to emerging technologies.

With the aim of enabling the widespread use of the methods utilized to answer the aforementioned question and meet the specific objectives underlying the goal of this study, 
this chapter presents the systematic methodology used so that it can be replicated in other product or technology contexts. This chapter is intended to present the methodologies developed during the study and to explain the course of each of the methodologies and the emergence of a categorization that is divided into three types.

The methodology that is meant to analyse the feasibility of applying an emerging technology in a given product was applied to three cases (Corda 2010), and is made up of five steps in order to analyze and compare the technologies. The intent of this methodology is to attempt to predict if the emergent technology is viable for application in a given product; as such, any technology that is incorporated, or has been incorporated, in a particular product is considered in the analysis and compared with the emerging technology that is intended to come to be incorporated in the same product. As a result of this methodology, one becomes aware of the performance of each selected technology in a given product, and gets to compare the performance of the product depending on the technology that enables the product features (specific and general) that were considered important for the analysis. This methodology is complemented with the use of another methodology, determining the causality of changes in technology on the external shape of the product.

The awareness of the strengths and weaknesses of each technology, in order to verify whether there is any viability in embedding an emerging technology in a product, is followed by the examination of the changes that have occurred by way of deployment of different technologies in the product. The methodology for determining the causality of changes caused by technology (changes in the external shape of the products analysed) also consists of five steps and connects the shape changes occurred in the products with the various technologies that incorporate each particular product.

It is important to provide a comprehensive perspective to support peers who intend to pursue the implementation of the two methods mentioned above, providing a (tripartite) categorization which is primarily a catalogue of the typological consequences of the influence of technology on the form of a product, as a result of applying the two methodologies presented in the process of technological product design.

\section{Methodologies developed}

This section is intended to communicate to peers (industrial designers and product engineers) the methodological results achieved. These concern stepwise methods to study technologies as determinants of a product's shape and to propose new shapes for products embedding emerging technologies. A number of technologies are considered in relation to a set of products, as a means to show how technology has influenced object shape and how new technologies (e.g. OLED - organic light emitting diodes, MEMS micro-electro-mechanical systems and energy harvesting) may promote archetype renewal.

Technology is a key player in today's society; it is the engine of our development and our innovation. Predicting its future uses necessitates systematic approaches, attempting to build future scenarios about the way science, technology, society and economy will evolve, in order to promote their benefits and make the most of the impacts that the future may bring (Glenn, Gordon \& Florescu 2008 as cited by Damrongchai \& Michelson 2009) . According to this report, the look to the future is optimistic as it will bring progress in various fields, including technology, which promises to have the ability to make the world 
work in a better way than it does today. There are a number of technologies that, according to Bengisu (2003) and Bengisu \& Bekhili (2006), will be the most promising technologies for the near future. This selection was established based on an approach that relates the number of scientific publications with the number of patents over the years. Those reports acknowledge the existence of many emerging technologies such as nanotechnology, biotechnology, super-insulating materials and structures, hydrogen storage and combustion technology. OLED, MEMS and Energy harvesting were chosen because they are emerging technologies that already are used and are soon to emerge on a large scale in the market. Additionally, because the technology and product pairs focused in this chapter were chosen simultaneously, the technology and the product had to be mutually compatible, so they could be articulated (technology and product) enabling the creation of new designs.

Organic Light Emitting Diodes (OLED), which are also called Light Emitting Polymers (LEP), are a technology which is at the forefront of bright screens and monitors, and has been steadily developing in recent years. OLEDs reached the media headlines in 2003 with one million units sold as part of a small application for an electric shaver from Philips, which gave an indication of the level of battery charge. Sometime later, a colour screen (OLED) also appeared with great success as a monitor on the back of a camcorder; Kodak (a major driving force in developing this technology) finally launched this image technology for the world market (Salmon 2004).

The development of MEMS, or micro-electromechanical systems, is responsible for an endless number of modern features and applications. This is a technology that has existed for some time but has expanded greatly in recent years, becoming an increasingly promising technology for the future. As we move into the third millennium, the number of applications for MEMS in our daily lives continues to increase, promoting continuously falling production costs for these devices (Beeby et al. 2004).

Energy harvesting $(\mathrm{EH})$ approaches, form a group of means to harvest energy, which due to scarcity of natural resources such as crude oil, and increasing pollution of the planet by some forms of energy production (such as polluting power plants), have began to gain importance and relevance in the production of clean energy. Increasingly there is awareness that every contribution that can save on energy from pollutant sources is welcome. As such, the use of personal devices, with the ability to produce a few milliwatt of power (a thousandth of the electric power needed for a common light bulb), coming from sources captured by forms of micro energy harvesting, are aligned with this purpose.

The first approach that was developed in the study reported in this chapter was to verify the potential application of an emerging technology in a given product, evaluating the application of OLED technology in TV sets. Five specific aspects and five general aspects were selected that were considered crucial to the performance and the quality of this product. In the second case, this methodology was used to predict the feasibility of applying $\mathrm{EH}$ technology (which is an approach to self-powering of technological devices, a grouping of forms of energy harvesting) to the clothes pressing warm iron, and likewise five general and five specific aspects were chosen that were considered relevant for this product and that enable the full unfolding of the methodology. The third case of deployment of this methodology consisted in attempting to assess the feasibility of application of MEMS to the vacuum cleaner. Each of the five steps that make up this methodology will be explained in this section, as well as their limitations. 
Another methodology is demonstrated in this section. It is intended to assist in determining the causality of changes in technology towards changes in the external shape of products. It hence aims at assessing technology's causality in relation to the changes that have occurred in the shape of the products under study (TV, iron and vacuum cleaner) as technology changed in them, attempting to predict which aspects of shape may arise and disappear with the implementation in these products of the selected emerging technologies. This methodology was applied first to the TV set, and was used to compare the shape in this product, depending on the technology that comprised it. Then the same methodology was employed to try to determine the aspects of form of warm clothes pressing irons according to the technology that they embody, and finally, to determine those aspects of the shape of vacuum cleaners, also depending on technology.

Observation of results and data taken from the application of these two methodologies gave rise to the need to create a comprehensive categorization of all cases of changes occurring in the form of products, which derive directly from the technology they incorporate, resulting in a categorization, consisting of three variations that embrace distinct types of shape changes in products.

\subsection{Feasibility analysis of the implementation of an emerging technology in a given product}

The methodology for feasibility analysis of the implementation of an emerging technology in a product consists of five steps (Table 2).

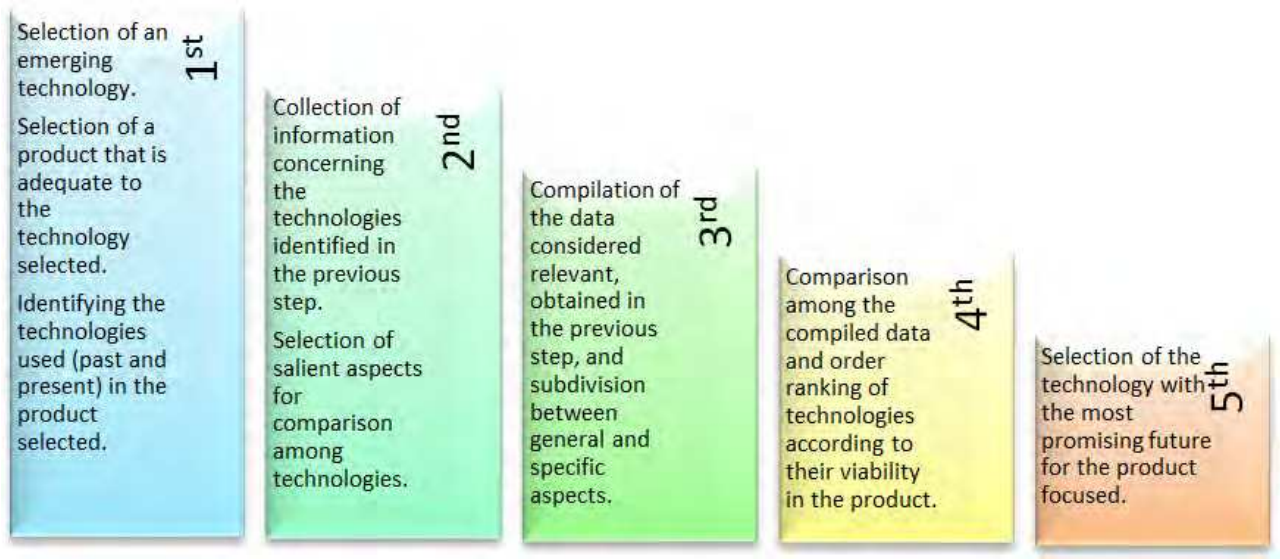

Table 2. Stages of the methodology for feasibility analysis, considering the implementation of an emerging technology in a product.

The first step of this methodology is implemented by choosing an emerging technology, which is intended for study, followed by the choice of product for which the test of feasibility of applying this technology is intended. This is followed by the identification of the technologies used and in use in this product, so that one can establish the comparison and proceed with the remaining actions prescribed in the methodology. The collection of information on technologies makes up the second step, in which one should gather as much information as possible, including the advantages and disadvantages of the technologies that the product uses, and even has used as well as the available data on the emerging 
technology. These enable drawing up a Table split between the advantages and disadvantages depending on the technology (view example in Table 3, developed for a specific technology - plasma, used on TVs). The third step consists in compiling the data that were considered relevant, after the drafting of the previous step, to create a Table containing the technologies selected in the first step, including the emerging technology (view example in Table 4 - developed for the vacuum cleaner and with the MEMS emerging technology in mind). Five general aspects considered important to the product (for which the study of the feasibility of applying the emerging technology is intended) and five specific issues which relate to factors that influence the product's performance are chosen. This Table is populated with a range of attributes ranging from acceptable, satisfactory, good, very good or excellent, to qualitatively describe the suitability of the technologies in the ten areas selected for comparison. The comparison of the data collected and the ranking of technologies in order of feasibility, comprise the fourth step of this methodology, which transforms the scale of words used in the previous step in a numerical scale ranging from one to five, where number one corresponds to acceptable and number five to excellent and the remaining values follow the order of the verbal scale.

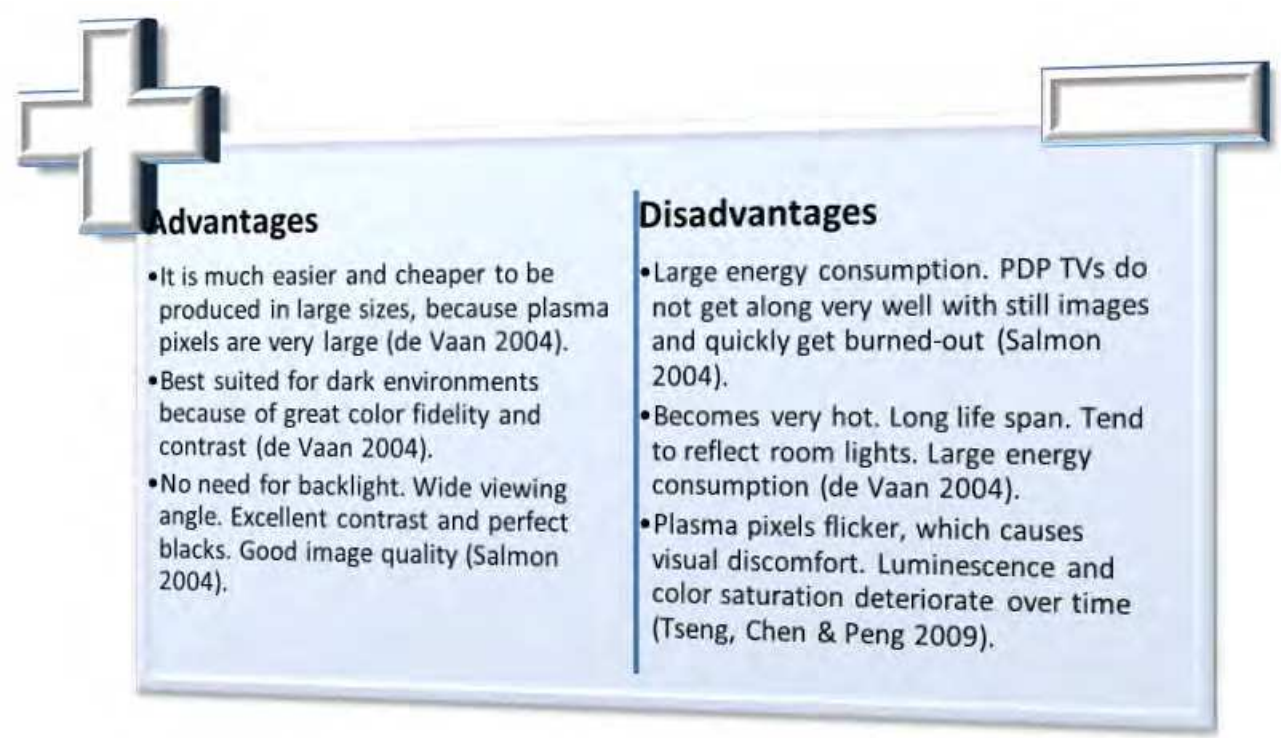

Table 3. Advantages and disadvantages of the PDP (Plasma Display Panel) technology in TV sets.

The fifth step entails drawing up a matrix (an example of such is given in Table 5, concerning technologies pertaining to the clothes ironing product) which sums up the values assigned in the fourth step, which in turn had been assigned by matching words and numbers in step three. General aspects are added, which enables concluding which technology has greater suitability, according to these aspects. Finally, the results of general and specific features are summed up, and it is then estimated which is the technology that is more feasible to apply the product selected in general (of the two kinds of aspects, both general and specific). 


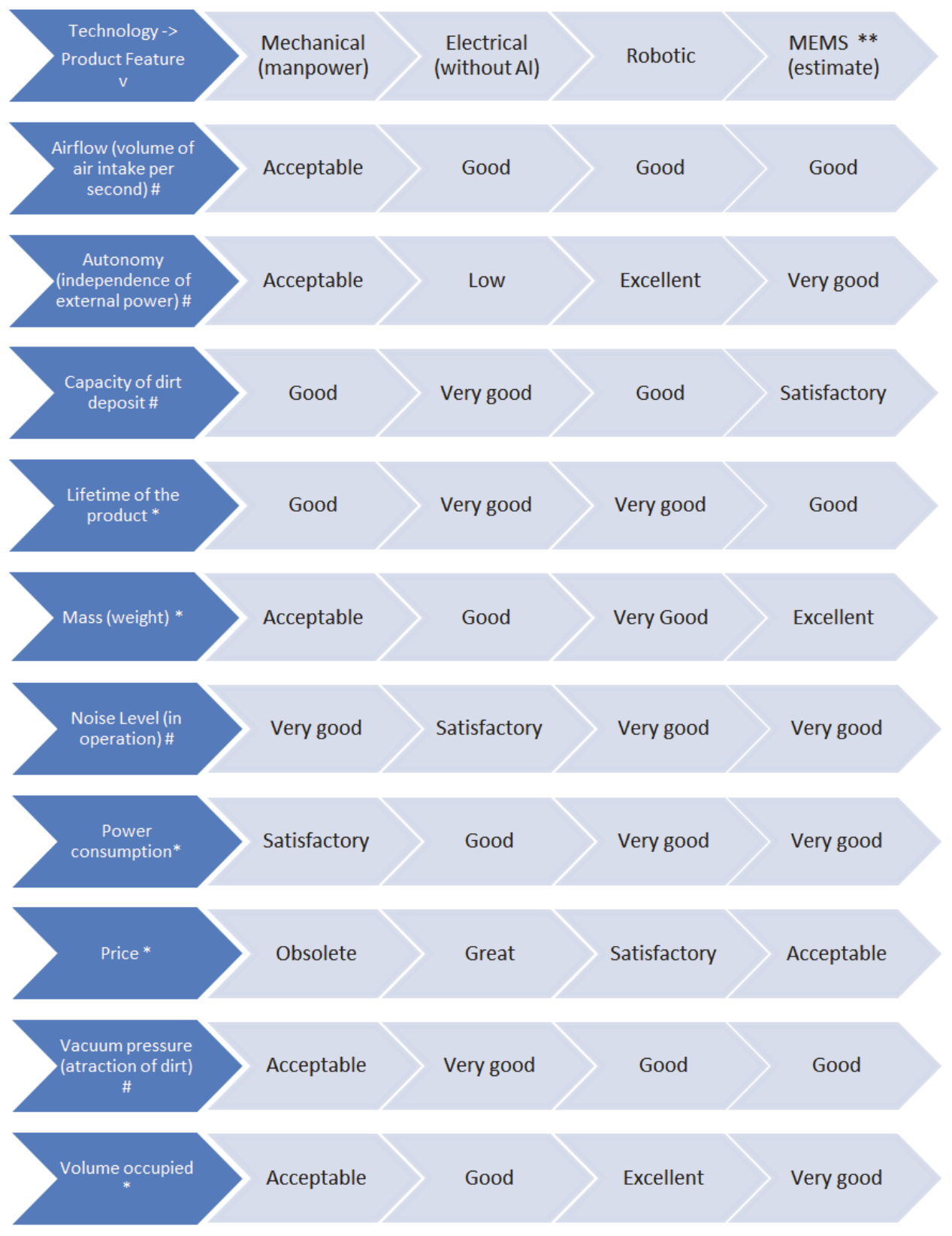

Legend: * - General characteristics, applicable to technological products; ** - Concerning the envisaged concept presented in Figure 6, \#- Specific features of the product family in question.

Table 4. Qualification of characteristics of technologies concerning the vacuum cleaner. 


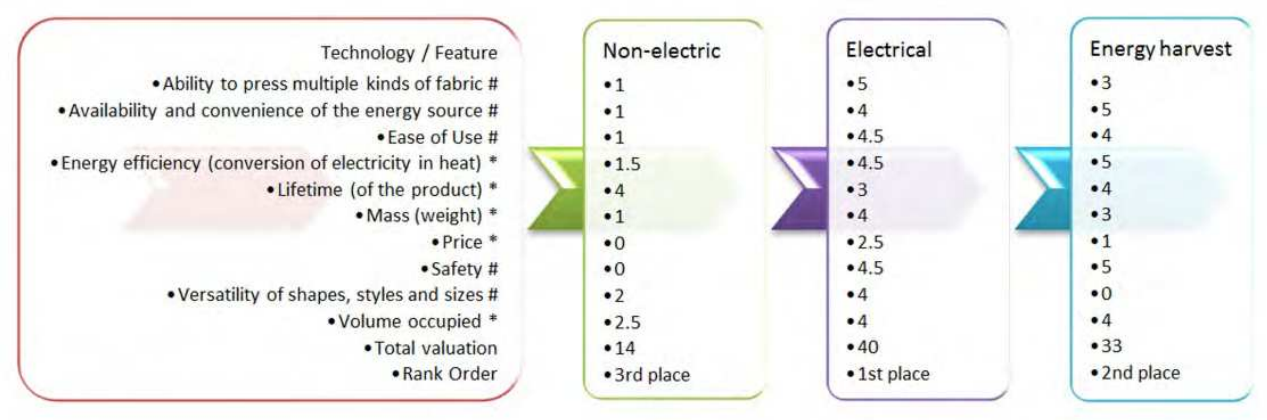

Legend: *- General characteristics, applicable to technology products \# - Specific to this particular type of product.

Table 5. Classification of technologies in comparison, for the product clothes pressing iron.

Tables 2 to 5 illustrate how the first methodology presented in this chapter unfolds; its first application demonstrated was to test the feasibility of application of OLED technology in televisions. It has proven very efficient and straightforward to conduct the entire process, as the abundance of data is large, which made it easier to collect relevant data, as well as performing the choice between specific and general issues for comparison between technologies. Another advantage, which allowed the development of this methodology, was that the emerging technology (OLED) has to be applied to the product concerned (TV) and as such values and considerations already existed and were already tested and proven for their practical implementation in the product. With regard to further application of this methodology in the case of the OLED technology within TVs, all the technologies selected for comparison are currently in use in this type of product, so this is not a product with a single dominant technology as is mostly the case for irons and vacuum cleaners. In the other two cases of deployment of this methodology, for EH and MEMS technology, the feasibility of implementing these procedures for the products iron and vacuum cleaner, respectively, was verified. Of particular importance was the fact that these technologies do not have widespread commercial application in the chosen products, and as such it became more difficult to collect data and make accurate analyses of the aspects in comparison between technologies. This was offset by the emergence of estimates and by basing the assessments on envisaged concepts developed for these two products with the incorporation of the emerging technologies. Another hardship found was that predecessors of the technologies used in the products iron and vacuum cleaner, are completely obsolete and are not used anymore, which also hampered the collection of some data.

It should be noted that this methodology is deemed suitable to application for most technologies, and serves the purposes of testing the feasibility of applying a particular technology within a product. It is a methodology that can be improved with the emergence of new data and of results of the application of emerging technology in the product focused.

\subsection{Determining causality in cases where technology changes the shape of the product}

The methodology for determining the causality of changes in technology, changes in the external shape of the products, is composed of five steps (Table 6). 


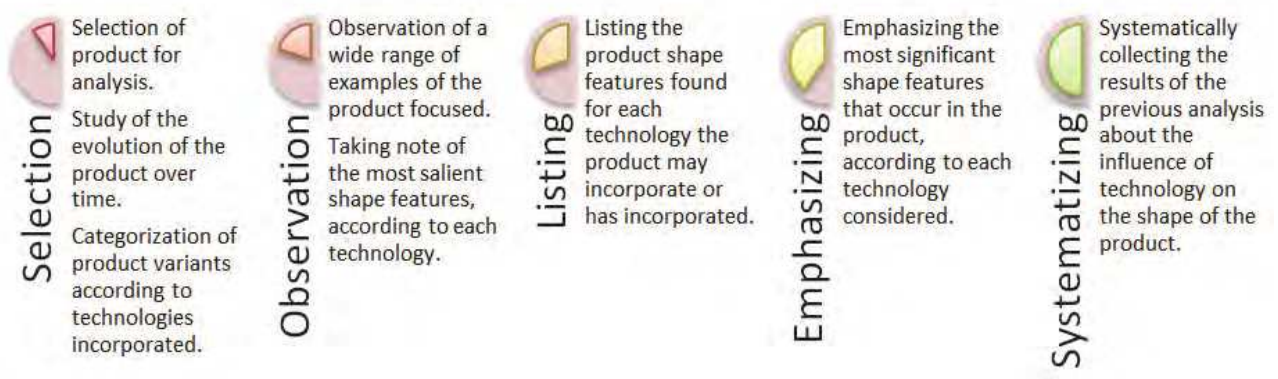

Table 6. Stages of the methodology for identification of causality of technological change in the shape alterations of a specific product over time.

The first step of this methodology is to choose the target product for the analysis in terms of form, which is followed by a historical study on the evolution of that product shape from its beginnings to the present. An analysis of the product is then made according to the technology that it incorporates, and may incorporate (the emerging technology that has been selected for the product). Then the form search begins, composed of the observation of a wide range of issues, consulting catalogues and product photos, which are used to infer all the salient features of shape and are organized according to the technology incorporated, completing the second step in this methodology. Creating Tables with the characteristics of the product form (which had been collected in the previous step) split according to the technology that the product incorporates, embodies the third step, which gives rise to a series of Tables. The fourth step consists of highlighting the most significant differences that occurred in the product shape according to technological change, in several Tables listing these changes. This does not only concern similarities, as gains and losses of form features are also of interest. The purpose of this step is to provide a systematic overview of the existing changes with the onset of another technology in a product. In the fifth step, the results from the previous step on the influence of technology in the form of a product are gathered in a systematic way. This enables describing the similarities in appearance, and the changes in form, for the product under study, on which a new technology is to be implemented. This step concludes the deployment of the methodology used to assist in determining technology's causality in changes in shape occurring in TVs, clothes pressing irons and vacuum cleaners.

The main limitation observed of the use of this methodology concerns the fact that in the case of irons and vacuum cleaners there is no model that uses the emerging technology that has been associated with each of these products. For television sets, it was not necessary to resort to the verification of the concept developed in the form of a TV with OLED technology, because actual examples already exist of this product incorporating OLED technology. The fact that in most products there is a vast variety of forms, is yet another hardship in the deployment of this methodology, to the extent that it would be impossible to analyze them all. Moreover, the existence of many technologies (mainly non-electric technologies, in the case of irons and vacuum cleaners) would yield very large lists, covering only a small set of products that used these technologies. As a way to overcome this obstacle, all non-electric technologies were considered jointly and a note was made of the 
common aspects of the products embedding them. In the case of the vacuum cleaner, nonelectric technologies were grouped together under the manpower label, comprising technologies that enhance the functionality of the product, such as tightening mechanisms, levers and mechanical cranks.

This methodology, which is deemed applicable to most types of products and technologies, is intended to convey a process to collect the aspects of form that make up a product depending on the technology it incorporates, and to relate the change of its shape with implementing a specific new technology in this product. Figures 1, 2 and 3, depict sketches of the salient shape contours of the three products analyzed, according to the type of technology that they embedded.
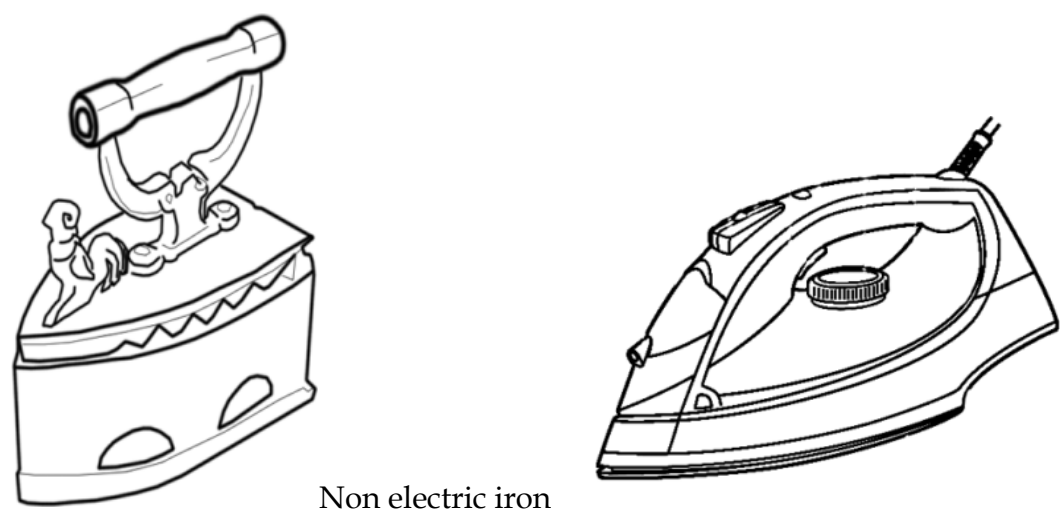

Electric iron

Fig. 1. The evolution of form in the modern clothes pressing iron.

While the fundamental shape archetype is unchanged as the clothes iron passed from non-electric to electric energy (Figure 1), over time there has been a gradual evolution of the form features in this product, resulting in a lighter and more streamlined product. Fundamentally, the product depicted in the right sketch still consists of a V-shaped metal base attached to a handle, and as such, this basic product archetype has endured over time.

The evolution of the shape of the TV set (Figure 2) has clearly been influenced by technology, in particular by the leap from CRT (Cathode Ray Tube) to LCD (Liquid Crystal Display). The most recent technological substitutes for LCD technology (Plasma, LED and OLED) have so far not promoted a fundamental change to the new archetype of the flat and thin TV set. This notwithstanding, there is a clear direction in the evolution of the shape of TV sets towards ultra-thin display panels (and flexible display panels are in the horizon).

Of the three products analysed in this chapter, the vacuum cleaner (Figure 3 ) is the case where more striking form changes took place as an effect of changing technologies and physical principles that make up its fundamental functionality. In this product, several archetypes of shape have coexisted over time, but clearly, each form archetype is associated to a particular technology, even if the same basic technology underlies several product form archetypes (this is especially true in the case of electric vacuum cleaners, from the preartificial intelligence era). 


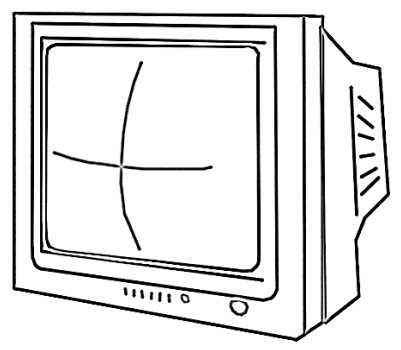

CRT TV

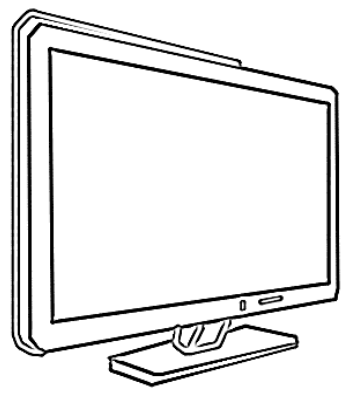

LCD TV
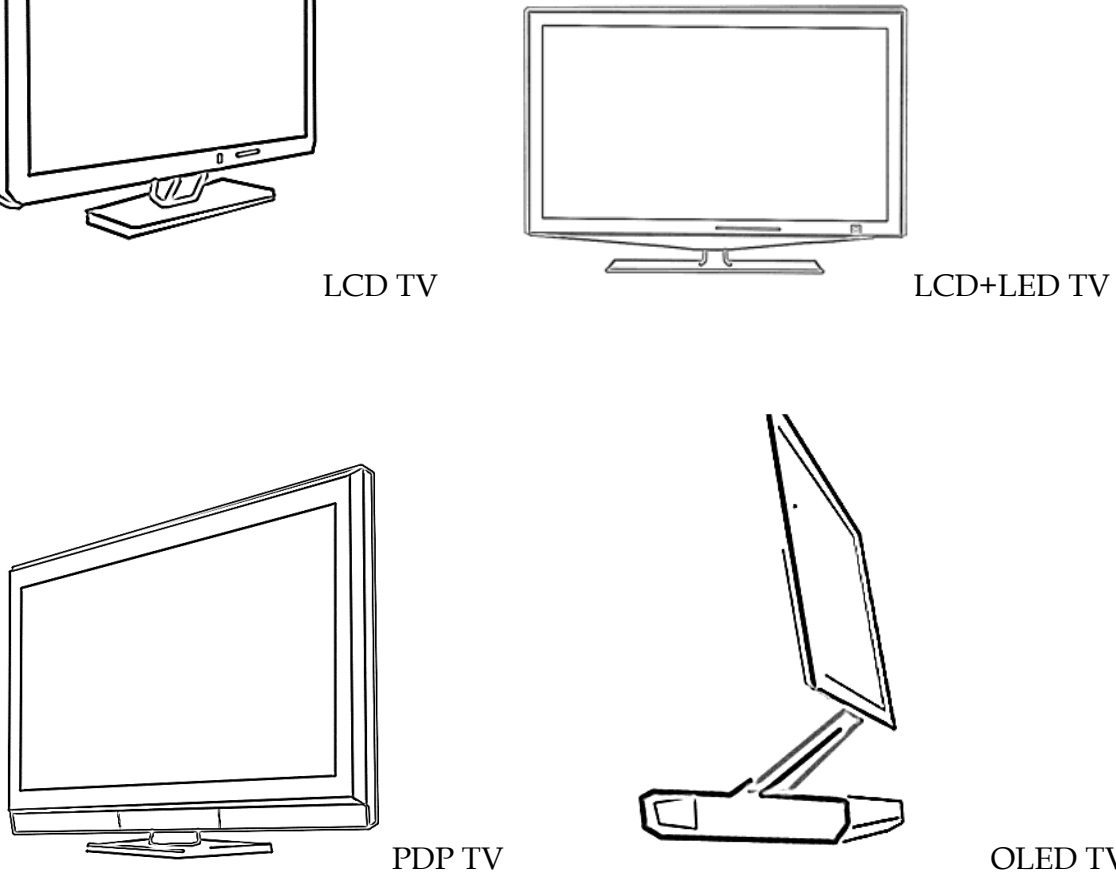

OLED TV

Fig. 2. The evolution of form in modern Television sets. 


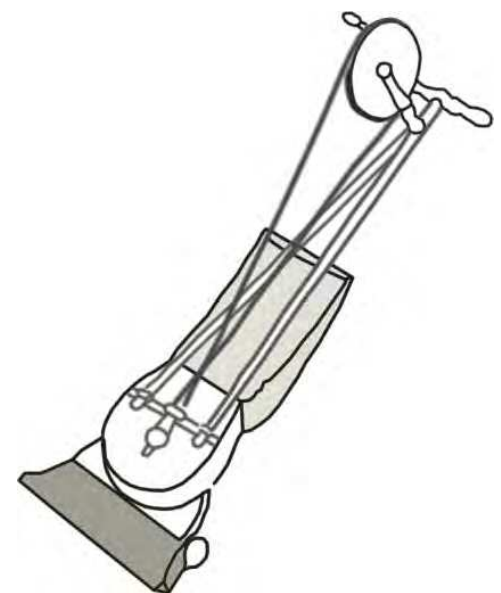

Mechanical predecessor to the vacuum cleaner

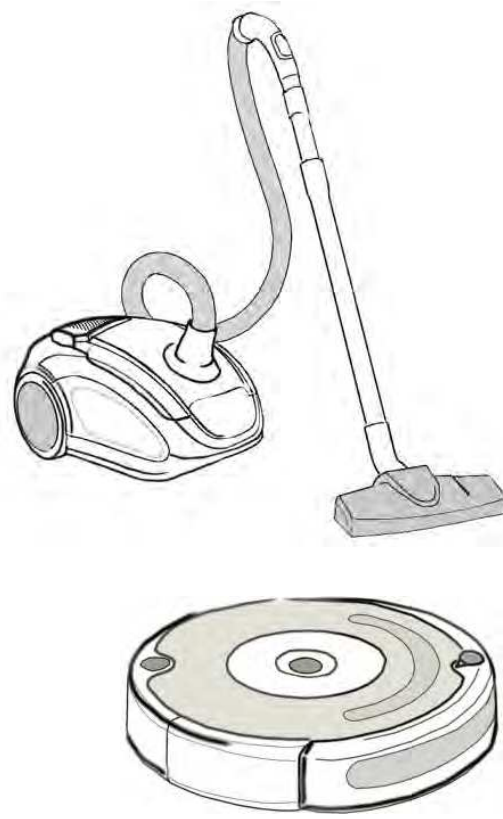

Electrical Vacuum cleaner (without artificial intelligence)

Robotic (automatic) vacuum cleaner

Fig. 3. The evolution of the form of the vacuum cleaner.

\subsection{Categorization encompassing three kinds of technology driven shape changes in products}

The methodology for determining the causality of changes in technology, changes in the external shape of the products, and the methodology for the analysis of feasibility of application of an emerging technology in a product, encompass the collection of data on the characteristics and performance of products according to the technology that they embody, as well as of the data on the morphological differences occurred due to that technology change. Encompassing the various kinds of form changes occurring in technology products, 
necessitates creating a categorization that considers the many changes in technology products. This is a tripartite categorization, which is divided into three variations.

This categorization served throughout the study reported in this chapter to frame the kind of change that occurred in the product after another technology incorporated it. Thus, changes were classified according to variations that occurred during the passage of television sets by various technologies (CRT, LCD, LCD + LED, PDP and OLED), as well as the shape changes resulting from the passage of irons by various technologies (non-electric, electric power and the principle of energy harvesting - EH), and, finally the changes in the vacuum cleaner with the emergence of various technologies (mechanical - human strength, electrical - without Artificial Intelligence, robotics and MEMS).

Thus it is possible to characterize the changes that occur in the products that were studied, within the following three categories:

1st type - change in the shape of the product caused by changing technology (appearance of a new technology or application of an existing technology but that was never used in this type of product) which leads to a visible shift in the product shape, yet the product as an object remains;

2nd type - product change, in situations where technology change is not reflected so much in changing the shape of the product, but is responsible for modification of performance and improved efficiency, keeping the product as an existing object and proceeding to surface shape change in order to signal the increased performance to consumers, and, finally, 3rd type - cessation of existence of the product as such, in situations where the change in technology leads to a deconstruction of the product as an object, leaving behind the archetypes and stereotypes hitherto associated with the product.

\section{Conclusion}

The aim of this chapter was to undertake a study about the influence of technology in the form of products that incorporate technology, using a standard methodology developed for this purpose. Examples of products and their shape changes over time were presented. Attempts to understand the extent to which these changes are consequences of the developments in technology were put forward, and the importance of technology as a determinant of the shape of products that incorporate technology was demonstrated based on three cases.

A review of the evolution of form, taking into account the technology of a selected range of consumer products that incorporate technology, with the aim of deconstructing archetypes that are fixed and propose new ideas was accomplished. In particular, a range of technologies that are foreseen for the future were considered, and these were also the subject of study in this contribution, and are expected to enable new designs and future forms for a great variety of products, which in some cases may be subject to a deconstruction of the archetype of the object's shape.

Selecting specific cases of products, from a historical perspective, one could see what have been the determinants of their shape, which led to the establishment of their archetypal form. A comparative methodology was developed, in order to hint at the role of technology as a determinant of the shape of products.

Understanding the importance of technology as a modelling influence for products' form, what role this has in the consumer society and what is its responsibility as a major element 
in the deconstruction of the archetypes of form was also focused in this contribution. The influence of technology in the transformation of products was demonstrated, considering three distinct types of alterations caused by changes in technology, in a tripartite view.

Following the study of the technologies, which was methodologically structured, and concerned the technologies embedded in the three products in analysis, in the past and with a forward view (technology that is foreseen for the future), a scenario is proposed, with new designs for the products that have been studied (Figures 4, 5 and 6). It is emphasized that the product as a physical object may disappear or may be dissolved in the environment or building architecture, with the advent of emerging technologies and their new capabilities.

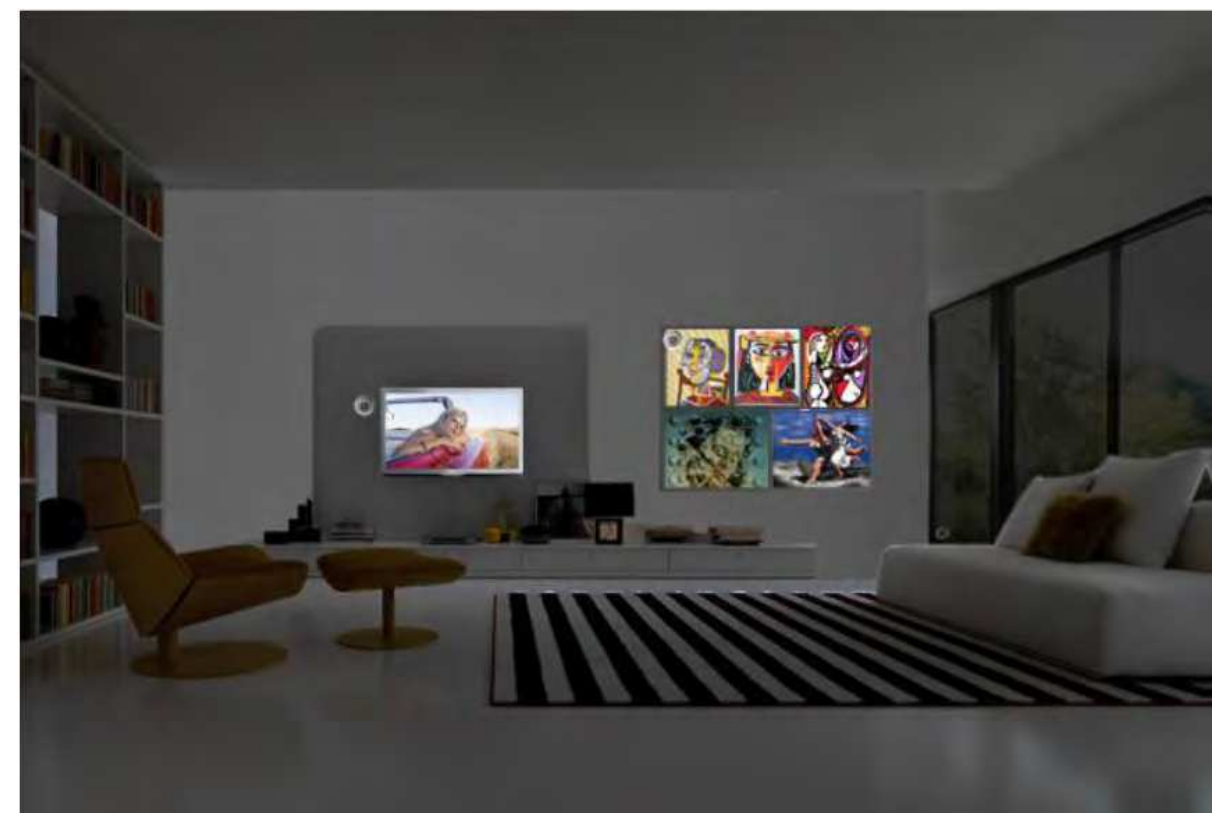

Fig. 4. Multiple applications of OLED technology in a living room (lighting, shading, dynamic wall art gallery, TV monitor).

In the case presented in Figure 4, dematerialization of a product (TV set) and its blending with architecture is enabled by the ultra-thin OLED technology. This technology also enables new applications, including, as depicted, lighting, shading and a dynamic wall art gallery. This case leads to question the role of industrial design in this foreseen evolution. Understanding people and their relation to artefacts, interaction design and concept creation (even if devoid of a three dimensional form) are bound to be design domains that industrial designers should focus on in supporting this kind of design endeavour.

The conceptual design presented for an energy self-sufficient travel iron (Figure 5), represents an archetypal leap from the traditional shape of this product, which caters to sustainability concerns. Independence of energy supply is bound to be another guiding theme to foster the creation by industrial designers of new product archetypes to perform functionality that had been tied to a fixed product concept. 

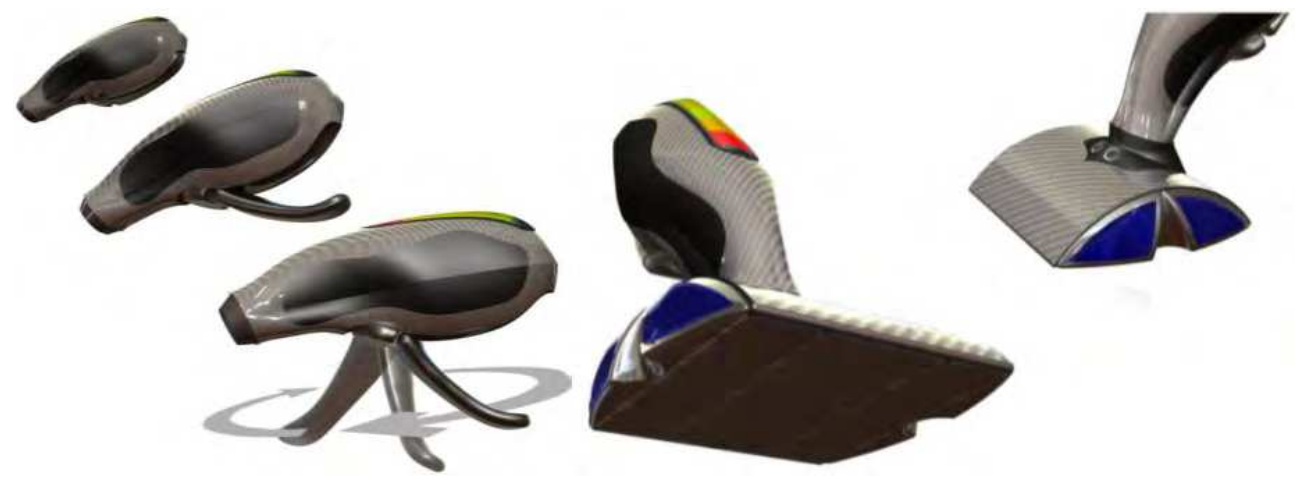

Fig. 5. Energy self-sufficient travel iron.
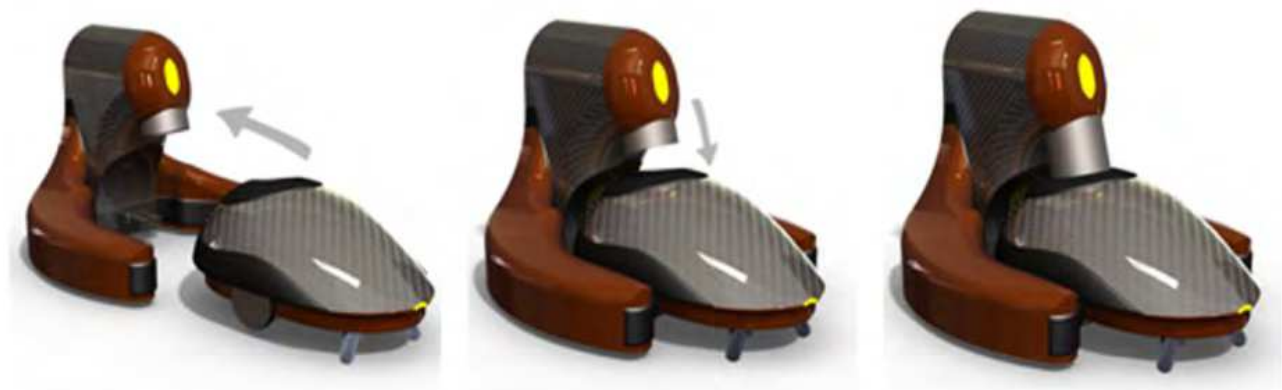

Fig. 6. System for unloading and battery charge of robotic vacuum cleaner.

The conceptual design presented in Figure 6 represents an incremental shape evolution from one of the current shape archetypes for vacuum cleaners. As growing automation and convenience for consumers proceeds, industrial designers are also bound to play an important role in establishing links with past era designs, and as such provide consumers in this digital age, objects that enable reminiscing of past eras, with a shape that cues their functionality, providing a deliberate a link with traditional shapes.

There are limitations in the methodologies presented in this chapter, which will be alleviated if the prerequisites that are necessary for their effective use are met. The methodologies and categorization are only deemed suitable for application in products that incorporate technology for their operation. It is important for the deployment of these methodologies to have knowledge on emerging technologies and on the history of the product or devices that have been used for implementation of a particular functionality.

There are some historical cases of technologies that have failed, and that were put aside, because there was an arrest of the market by a technology already implemented. This happened for example with Sony's Beta video system, which was of higher quality than Philip's VHS (Video Home System), but the latter prevailed (despite the better quality of the Beta video system), because films existed in greater quantities in the VHS format, which led to the decrease of availability of films in Beta format. There is no guarantee that the three 
emerging technologies selected will have a future in the market, or even a future in the product (or application) that has been studied. The fact that emerging technologies are still developing, makes their performance characteristics modifiable and changeable in a short time span. It is also noteworthy that the current concerns about environmental sustainability have led governments to constrain the free operation of markets which can alter the dynamics of competition for emerging technologies, seeking to accelerate the implementation of more sustainable alternatives, and restricting the widespread adoption of other technologies, which may discourage the implementation of some emerging technologies.

\section{References}

Baudrillard, J. (1995). Sociedade de consumo [in Portuguese - The consumer society], Lisboa: edições 70 .

Beeby, S., Ensell, G., Kraft, M. \& White, N. (2004). MEMS Mechanical Sensors, Southampton, United Kingdom: Artech House.

Bengisu, M. (2003). Critical and emerging technologies in materials, manufacturing, and industrial engineering: a study for priority setting, Scientometrics, Vol. 58, No. 3, 473-487.

Bengisu, M. \& Bekhili, R. (2006). Forecasting emerging technologies with the aid of science and technology databases, Technological Forecasting \& Social Change, Vol.73, 835844.

Bloch, Peter H. (1995). Seeking the ideal form: product design and consumer response, Journal of Marketing, 59(3), 16-29.

Corda, F. A. A. (2010). A tecnologia como determinante da forma dos objectos [in Portuguese - Technology as a determinant of object shape], Master of Science Dissertation in Technological industrial Design, Dept. Electromechanical Engineering, Universidade da Beira Interior, Portugal. Available on-line at http://webx.ubi.pt/ denis/MDIT/dissertacao_FilipeCorda.pdf

Crilly, N., Moultrie, J. \& Clarkson, P.J. (2009). Shaping things: intended consumer response and the other determinants of product form, Design Studies, 30(3), 224254.

Damrongchai, N. \& Michelson, S.E. (2009). The Future of Science and Technology and propoor applications, Foresight, 11(4), 51-65.

Glenn, J.C., Gordon, T.J. \& Florescu, E. (2008). 2008 State of the Future. The Millennium Project, Washington, DC.

Hales, C., (1991). Analysis of the Engineering Design Process in an Industrial Context, Eastleigh, UK: Gants Hill Publications.

Lewis, W. P., Bonollo, E., (2002), An analysis of professional skills in design: implications for education and Research. Design Studies No.23, pp. 385-406.

Roozenburg, N. F. M. \& Eekels, J., (1995). Product Design: Fundamentals and Methods, Chichester: John Wiley \& Sons.

Salmon, R. (2004). The changing world of TV display - CRT challenged by flat-panel display, EBU technical review, April 2004, pp.1-9. 
Tseng, F., Cheng, A., \& Peng, Y. (2009). Assessing market penetration combining scenario analysis, Delphi, and the technological substitution model: The case of the OLED TV market, Technological Forecasting \& Social Change, Vol.76, 897909.

de Vaan, A. J. S. M. (2004). Competing display technologies for the best image performance, Journal of the SID, 15, 657-666. 


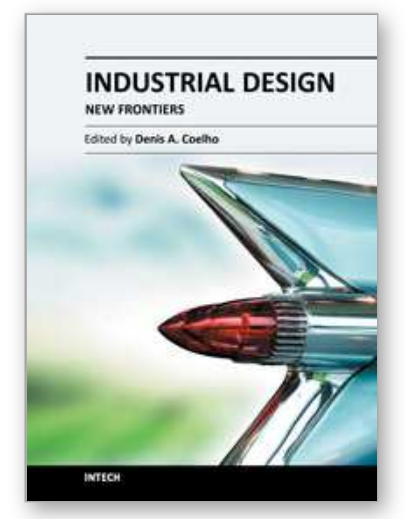

\author{
Industrial Design - New Frontiers \\ Edited by Prof. Denis Coelho
}

ISBN 978-953-307-622-5

Hard cover, 190 pages

Publisher InTech

Published online 09, November, 2011

Published in print edition November, 2011

A new breed of modern designers is on the way. These non-traditional industrial designers work across disciplines, understand human beings, as well as business and technology thus bridging the gap between customer needs and technological advancement of tomorrow. This book uncovers prospective designer techniques and methods of a new age of industrial design, whose practitioners strive to construct simple and yet complex products of the future. The novel frontiers of a new era of industrial design are exposed, in what concerns the design process, in illustrating the use of new technologies in design and in terms of the advancement of culturally inspired design. The diverse perspectives taken by the authors of this book ensure stimulating reading and will assist readers in leaping forward in their own practice of industrial design, and in preparing new research that is relevant and aligned with the current challenges of this fascinating field.

\title{
How to reference
}

In order to correctly reference this scholarly work, feel free to copy and paste the following:

Denis A. Coelho and Filipe A. A. Corda (2011). Technology as a Determinant of Object Shape, Industrial Design - New Frontiers, Prof. Denis Coelho (Ed.), ISBN: 978-953-307-622-5, InTech, Available from: http://www.intechopen.com/books/industrial-design-new-frontiers/technology-as-a-determinant-of-object-shape

\section{INTECH}

open science | open minds

\section{InTech Europe}

University Campus STeP Ri Slavka Krautzeka 83/A 51000 Rijeka, Croatia Phone: +385 (51) 770447 Fax: +385 (51) 686166 www.intechopen.com

\author{
InTech China \\ Unit 405, Office Block, Hotel Equatorial Shanghai \\ No.65, Yan An Road (West), Shanghai, 200040, China \\ 中国上海市延安西路65号上海国际贵都大饭店办公楼 405 单元 \\ Phone: +86-21-62489820 \\ Fax: +86-21-62489821
}


(C) 2011 The Author(s). Licensee IntechOpen. This is an open access article distributed under the terms of the Creative Commons Attribution 3.0 License, which permits unrestricted use, distribution, and reproduction in any medium, provided the original work is properly cited. 